\title{
A formação profissional nos cursos de licenciatura e o exercício do magistério na educação básica: intenções, realizações e ambiguidades
}

\section{Professional formation in higher education institutions and pedagogical practice in basic education: intentions, realizations and ambiguities}

\author{
Carlos Antonio Giovinazzo Junior ${ }^{*}$
}

\begin{abstract}
RESUMO
É realizada a análise de dois dos documentos produzidos, visando regular e orientar a formação inicial de profissionais da educação básica (Resolução $\mathrm{CNE} / \mathrm{CP} \mathrm{N}^{\circ} 1 / 06$ e o Parecer CNE/CP N $2 / 15$ ). Toma-se as noções de racionalidade tecnológica e de pseudoformação, formuladas por Marcuse e Adorno, para examinar o modelo de formação docente estabelecido pelos membros do Conselho Nacional de Educação (CNE). Também são cotejadas informações de ambas as fontes tendo em vista a reflexão sobre as principais tendências presentes na formação de professores no Brasil. Se a racionalidade tecnológica produz disposições que exprimem a maneira como a dominação se consubstancia na sociedade administrada e se a pseudoformação é a forma de socialização predominante, refletindo a alienação que caracteriza a relação dos indivíduos com homens, coisas e natureza, a análise permite afirmar que as contradições, características de sociedades marcadas pela desigualdade e opressão, o que, por sua vez, produz incertezas sobre a função da escola, estão presentes nos dilemas implicados na docência. $\mathrm{O}$ modelo de formação inicial para o magistério prioriza a formação técnica em detrimento da articulação entre educação, formação docente e política; e
\end{abstract}

DOI: $10.1590 / 0104-4060.49147$

* Pontifícia Universidade Católica de São Paulo. Faculdade de Educação/PEPG em Educação: História, Política, Sociedade. São Paulo, São Paulo, Brasil. Rua Ministro Godoi, 969 - $4^{\circ}$ andar - sala 4E-19. Bairro: Perdizes. CEP: 05015-901. E-mail:cgiovinazzo@pucsp.br. 
os recursos mobilizados para isso estão estreitamente ligados ao caráter instrumental conferido à profissionalização dos professores, com a redução do ato de ensinar à técnica didática e da teoria a um conjunto de conhecimentos a serem aplicados no processo pedagógico, contanto que certos princípios sejam corretamente observados.

Palavras-chave: Formação de professores. Curso de Pedagogia. Diretrizes curriculares. Exercício do magistério. Licenciaturas.

\begin{abstract}
This is an analysis of two documents produced to regulate and guide the initial formation of basic education professionals (CNE/CP No. 1/06 and the CNE/CP No. 2/15). Based on Notions of technological rationality and semi-formation, formulated by Marcuse and Adorno, are used to examine the teacher education model established by members of the National Education Council. Both sources are considered in order to reflect on major trends that characterize the teacher formation in Brazil. If technological rationality produces layouts which express how domination takes place in the administered society, if semi-formation is the predominant form of socialization, reflecting the alienation that characterizes the relationship of individuals with people, things and nature, the analysis allows us to claim that the typical contradictions of societies marked by inequality and oppression, that in turn create uncertainties about the function of the schools, are present in the dilemmas implicated in teaching. The initial formation model prioritizes technical education at the expense of articulation between instruction, teacher formation and political education, and the resources called into play for this are closely linked to the instrumental character conferred on the professionalization of teachers, by reducing the act of teaching to didactic technique and theory to a knowledge set to be applied in the educational process in accordance with certain principles that must be properly observed.
\end{abstract}

Keywords: Teacher formation. Pedagogy. Curriculum guidelines. Teaching practice. Graduation for teachers in higher education.

\title{
Introdução
}

Neste artigo são apresentadas algumas considerações sobre dois documentos que devem regular a formação de professores no Brasil, assinalando trechos nos quais são destacados os princípios e os fundamentos da formação 
profissional para o magistério e aspectos sobre os quais o currículo dos cursos de licenciatura deve incidir.

Nos últimos 20 ou 30 anos, assistimos inúmeras iniciativas por parte daqueles que ocupam lugares de destaque no debate em torno da educação escolar e da formação de professores, cujos objetivos foram a criação de condições para que o sistema educacional brasileiro ganhasse em organização e racionalidade. Boa parte dos envolvidos no debate e nas ações políticas tem como principal preocupação a melhoria da qualidade do trabalho educativo realizado com crianças, adolescentes e jovens, o que só seria alcançado se as escolas obedecessem a certos princípios e fundamentos definidos nacionalmente e se possuíssem condições objetivas (autonomia administrativa, recursos financeiros, apoio para desenvolver infraestrutura etc.). É bem verdade que nunca foi consenso o que se entende por qualidade em educação, com alguns focalizando o rendimento dos alunos e os resultados das escolas e outros apontando que a qualidade deve ser medida também por outros indicadores, a exemplo do clima institucional, da gestão pedagógica e da experiência de socialização proporcionada aos alunos.

No que diz respeito ao sistema de ensino, é possível identificar a criação e a consolidação de alguns mecanismos políticos e financeiros que sustentaram a política educacional e que contribuíram para que as redes de escolas (municipais, estaduais e federal) pudessem ser estruturadas e organizadas com base em diretrizes que cobrem todo o território nacional. São os casos do Fundo de Desenvolvimento da Educação Básica (FUNDEB), do Sistema de Avaliação da Educação Básica (SAEB), da Lei de Diretrizes e Bases da Educação Nacional (LDBEN), dos Parâmetros Curriculares Nacionais (PCN) e das diretrizes curriculares estabelecidas para cada disciplina escolar e para os vários níveis da educação básica (educação infantil, ensino fundamental e ensino médio).

Isso também pode ser observado no caso da formação de professores para a educação básica. Aqui são analisados dois documentos que podem ser incluídos nessa tendência de busca pela integração do sistema educacional no Brasil: a Resolução CNE/CP No 1, de 15/05/2006, que instituiu Diretrizes Curriculares Nacionais para o Curso de Graduação em Pedagogia, e o Parecer $\mathrm{CNE} / \mathrm{CP} \mathrm{N}^{\circ}$ 2, de 09/06/2015, que apresenta as Diretrizes Curriculares Nacionais para a Formação Inicial e Continuada dos Profissionais do Magistério da Educação Básica. Considera-se que esses documentos apresentam variados aspectos merecedores de exame mais minucioso, pois uma leitura rápida pode dar a entender que o fato de uma multiplicidade de situações ser contemplada, exprimindo certa concepção mais ampliada sobre a docência e o trabalho do professor, denota que os problemas enfrentados por professores formadores, estudantes e instituições de ensino superior, observadas até então, foram dirimidos. O que se pretende demonstrar é que, mesmo sem que esteja explícito, 
prevalece uma situação em que é priorizada a formação técnica em detrimento de uma proposta que possa articular educação, formação docente e política, já que nada é formulado em termos de fazer com que os cursos de licenciatura ganhem em consistência teórica.

Nas diretrizes curriculares para o curso de Pedagogia (BRASIL, 2006), lugar privilegiado de formação de professores para a educação infantil ( 0 a 5 anos) e para os anos iniciais do ensino fundamental, observa-se que são esperadas as seguintes capacidades do egresso do curso e futuro professor, entre outras tantas:

I - atuar com ética e compromisso com vistas à construção de uma sociedade justa, equânime, igualitária;

II - compreender, cuidar e educar crianças de zero a cinco anos, de forma a contribuir, para o seu desenvolvimento nas dimensões, entre outras, física, psicológica, intelectual, social;

III - fortalecer o desenvolvimento e as aprendizagens de crianças do Ensino Fundamental, assim como daqueles que não tiveram oportunidade de escolarização na idade própria;

[...]

VI - ensinar Língua Portuguesa, Matemática, Ciências, História, Geografia, Artes, Educação Física, de forma interdisciplinar e adequada às diferentes fases do desenvolvimento humano;

VII - relacionar as linguagens dos meios de comunicação à educação, nos processos didático-pedagógicos, demonstrando domínio das tecnologias de informação e comunicação adequadas ao desenvolvimento de aprendizagens significativas;

$[\ldots]$

IX - identificar problemas socioculturais e educacionais com postura investigativa, integrativa e propositiva em face de realidades complexas, com vistas a contribuir para superação de exclusões sociais, étnico-raciais, econômicas, culturais, religiosas, políticas e outras;

$\mathrm{X}$ - demonstrar consciência da diversidade, respeitando as diferenças de natureza ambiental-ecológica, étnico-racial, de gêneros, faixas geracionais, classes sociais, religiões, necessidades especiais, escolhas sexuais, entre outras;

$[\ldots]$

XIV - realizar pesquisas que proporcionem conhecimentos, entre outros: sobre alunos e alunas e a realidade sociocultural em que estes desenvolvem suas experiências não escolares; sobre processos de ensinar e de aprender, em diferentes meios ambiental-ecológicos; sobre propostas curriculares; e sobre organização do trabalho educativo e práticas pedagógicas [...]. (BRASIL, 2006, p. 2-3). 
Ambiciona-se que a atuação do professor dê conta de praticamente toda a complexidade do fenômeno educativo. Desse modo, as habilidades e capacidades incidem sobre aspectos políticos (promoção de uma sociedade justa e eliminação da exclusão e da discriminação sofrida por certos grupos sociais), sociais (valorização da diversidade e promoção da relação entre a escola e a família), psicológicos (promoção do desenvolvimento integral da criança pequena), além daquelas que se referem ao dia a dia da vida escolar (promoção das aprendizagens dos alunos, inclusão dos que apresentam diversidade que implicam em necessidades diferenciadas e ensino das disciplinas e seus conteúdos). Também se almeja que os futuros professores possuam conhecimentos e habilidades que os habilite a realizar a gestão educacional (promoção da interdisciplinaridade, avaliação das políticas governamentais e organização do trabalho pedagógico). Por fim, objetiva-se no curso de Pedagogia o desenvolvimento, em seus egressos, de habilidades necessárias para a realização de pesquisa científica e de uso competente de instrumentos, técnicas e meios de informação e comunicação.

Longe de subdimensionar a importância e a necessidade de que todos os aspectos listados, e os seus conteúdos, façam parte do currículo dos cursos de formação de professores, chama-se a atenção para a dificuldade de dotar os estudantes de condições para o exercício do magistério em apenas 3.200 horas de curso. Parece não restar dúvida quanto à existência de variáveis e de condições objetivas (de ordem política, econômica, social e cultural) que determinam e muitas vezes se tornam obstáculos ao trabalho do professor. Portanto, sua formação não pode prescindir de situar em que tipo de sociedade e quais problemas os seus membros enfrentam, seja na escola ou fora dela. No entanto, o aumento das atribuições conferidas ao professor, cujas habilidades precisam ser desenvolvidas muito precocemente (na formação inicial), pode tirar o foco do que é talvez a principal razão de ser de sua atividade: o ensino de conteúdos (ligados ou não diretamente à disciplina para a qual o docente está preparado), de modo que seus alunos tenham totais e plenas condições de aprenderem e se apropriarem do que foi ensinado.

Seja como for, aquilo que o professor poderia aprender com sua experiência - por exemplo, depois de alguns anos atuando na mesma escola, junto com seus colegas, podem propor soluções para os problemas de indisciplina ou provenientes da relação com a comunidade -, é cobrado dele já no início do exercício do magistério e, consequentemente, do curso de formação inicial. Que fique claro: não se está advogando em favor da formação continuada ou em serviço, em contraposição à inicial, mas enfatizando que o curso de formação inicial não tem potencial para preencher todas as lacunas reconhecidas e projetadas na licenciatura, embora todas elas estejam localizadas no próprio campo da educação. Em certa medida, por se responsabilizar o professor pelo fracasso 
da escola pública e cobrar-lhe que assume o compromisso pela reversão desse quadro, os profissionais que atuam como formadores (nos cursos de licenciatura) também recebem parte dessa responsabilidade.

É evidente que os cursos de formação inicial de professores merecem grande parte das críticas que recebem, principalmente aquelas que apontam para a superficialidade e incoerência de seus projetos de curso e para a pouca consistência teórica, decorrendo disso o fato de que as próprias disputas e embates da área educacional não são desenvolvidos e aprofundados nesses cursos. É justamente essa situação que os redatores das diretrizes para licenciatura em Pedagogia não conseguem alterar, pois a gama de conteúdos e de situações com as quais o futuro professor deve entrar em contato não permite qualquer aprofundamento. Vejamos parte dos conteúdos que devem ser contemplados na matriz curricular, que é composta de três núcleos conforme art. $6^{01}$ (BRASIL, 2006): estudos básicos, aprofundamento e diversificação de estudos e estudos integradores.

- conhecimentos que contribuam para o desenvolvimento das pessoas, das organizações e da sociedade;

- princípios da gestão democrática em espaços escolares e não escolares; - conhecimentos de processos de desenvolvimento de crianças, adolescentes, jovens e adultos, nas dimensões física, cognitiva, afetiva, estética, cultural, lúdica, artística, ética e biossocial;

- diagnóstico sobre necessidades e aspirações dos diferentes segmentos da sociedade, relativamente à educação;

- estudo da Didática, de teorias e metodologias pedagógicas, de processos de organização do trabalho docente;

- decodificação e utilização de códigos de diferentes linguagens utilizadas por crianças, além do trabalho didático com conteúdos, pertinentes aos primeiros anos de escolarização, relativos à Língua Portuguesa, Matemática, Ciências, História e Geografia, Artes, Educação Física;

- estudo das relações entre educação e trabalho, diversidade cultural, cidadania e sustentabilidade;

- atenção às questões atinentes à ética, à estética e à ludicidade, no contexto do exercício profissional, em âmbitos escolares e não escolares, articulando o saber acadêmico, a pesquisa, a extensão e a prática educativa; - avaliação, criação e uso de textos, materiais didáticos, procedimentos e processos de aprendizagem que contemplem a diversidade social e cultural da sociedade brasileira;

1 Aqui não são citados todos os 18 itens que constam nas diretrizes. Optou-se por transcrever apenas parte dos conteúdos arrolados porque sua apresentação na íntegra ocuparia um espaço desnecessário no artigo, uma vez que a intenção é tão somente demonstrar a grande quantidade de temas que os futuros professores devem estudar na formação inicial. 
- atividades práticas, de modo a propiciar vivências, nas mais diferentes áreas do campo educacional.

A variedade e amplitude de conteúdos são tão extensas que tornam bastante difícil ao aluno se fixar em alguma especificidade e desenvolver estudos mais aprofundados. Soma-se a esse fato as indefinições históricas presentes na Pedagogia. Embora nas diretrizes estejam claras as orientações que tornam o curso lócus privilegiado para a formação inicial de professores para a educação infantil e para os primeiros anos do ensino fundamental, ainda permanece a noção de que o pedagogo é, antes de tudo, um especialista e uma espécie de profissional técnico da educação. No texto das diretrizes, o curso de Pedagogia é assim definido:

Art. $2^{\circ}$ As Diretrizes Curriculares para o curso de Pedagogia aplicam-se à formação inicial para o exercício da docência na Educação Infantil e nos anos iniciais do Ensino Fundamental, nos cursos de Ensino Médio, na modalidade Normal, e em cursos de Educação Profissional na área de serviços e apoio escolar, bem como em outras áreas nas quais sejam previstos conhecimentos pedagógicos. (BRASIL, 2006, p. 1).

Entretanto, logo em seguida são ampliadas as possibilidades de atuação do pedagogo:

Parágrafo único. [do Art. $4^{\circ}$ ] As atividades docentes também compreendem participação na organização e gestão de sistemas e instituições de ensino, englobando:

I - planejamento, execução, coordenação, acompanhamento e avaliação de tarefas próprias do setor da Educação;

II - planejamento, execução, coordenação, acompanhamento e avaliação de projetos e experiências educativas não escolares;

III - produção e difusão do conhecimento científico-tecnológico do campo educacional, em contextos escolares e não escolares. (BRASIL, 2006, p. 2).

Como se pode ver, o egresso da licenciatura em Pedagogia é professor e pedagogo, o que envolve ser especialista e pesquisador em educação, isso 
o torna apto a exercer a gestão de escolas e de sistemas de ensino e a atuar em "contextos não escolares". As diretrizes, nesse sentido, são uma tentativa de integrar todas essas possibilidades de exercício profissional, conferindo "multidimensionalidade" ao curso. As consequências não poderiam ser outras: pouca consistência teórica, uma vez que as disciplinas e atividades ligadas aos chamados fundamentos da educação têm carga horária sempre insuficiente; o foco recai na formação técnica do pedagogo, muito embora o conhecimento adquirido no curso ainda não esteja solidificado. Tudo isso indica que a fragilidade da formação intelectual do pedagogo e do professor dos primeiros anos do ensino fundamental e da educação infantil ainda não foi superada. E o indicador dessa realidade é a constante presença nas políticas educacionais de propostas de formação continuada e em serviço. Entende-se por formação intelectual o que Theodor W. Adorno escreveu quando analisava o processo de habilitação de professores na Alemanha na década de 1960: os futuros professores devem ser capazes de "[...] ir além do seu aprendizado estrito, na medida em que desenvolvem uma reflexão acerca de sua profissão, ou seja, pensam acerca do que fazem, e também refletem acerca de si mesmos". (ADORNO, 1995a, p. 54). Assim os impasses e ambiguidades do curso de Pedagogia só poderão ser superados se seus profissionais forem capazes de refletir sobre os limites (não somente as possibilidades) de sua prática e sobre a situação objetiva da própria profissão.

Foram apresentados alguns apontamentos referentes às diretrizes que orientam o curso de Pedagogia (BRASIL, 2006). A partir deste ponto outras considerações são tecidas com o fito de analisar as Diretrizes Curriculares Nacionais para a Formação Inicial e Continuada dos Profissionais do Magistério da Educação Básica, segunda parte do parecer CNE/CP No 2/2015, emitido pelo Conselho Nacional de Educação em 9/6/2015.

$\mathrm{O}$ relator do parecer e das diretrizes indica a necessidade de conferir “organicidade" tanto ao trabalho pedagógico como à formação de professores, partes integrantes do projeto nacional de educação:

a consolidação das normas nacionais para a formação de profissionais do magistério para a educação básica é indispensável para o projeto nacional da educação brasileira, em seus níveis e suas modalidades da educação básica, tendo em vista a abrangência e a complexidade da educação de modo geral e, em especial, a educação escolar inscrita na sociedade. (BRASIL, 2015, p. 21).

São destacados alguns princípios que necessitariam ser estabelecidos no campo educacional. Desses derivam dois compromissos: a) público, para garantir 
o direito à educação de qualidade, esta última assentada em bases científicas e técnicas; b) político, para consolidar a soberania nacional e desenvolver uma nação democrática, justa, inclusiva e que proporcione a emancipação e a valorização da diversidade.

Já nesse preâmbulo se observa a incorporação de uma série de temas introduzidos no debate educacional nos últimos anos, o que denota uma característica presente na formulação de outros documentos oficiais da área da educação: a tendência de incluir tudo o que está em disputa e todos os interesses dos grupos representados no debate. Se, por um lado, isso expressa o processo de negociação envolvido, por outro, pode se tornar um obstáculo à fixação de objetivos e prioridades fundamentais e à focalização no que realmente importa. Aliás, parece ser exatamente o que acontece, pois é difícil identificar o básico e o principal na política de formação de professores - tome-se como exemplo a ênfase conferida à formação inicial e continuada.

Ambos os momentos são tratados de modo articulados e recebem o mesmo destaque. Observe-se como é justificada a formulação das diretrizes: devem ser definidas "[...] diretrizes conjuntas para a formação inicial e continuada dos profissionais do magistério da educação básica, bem como as políticas voltadas para maior organicidade desta formação" (BRASIL, 2015, p. 21). Chama atenção o fato de a formação de professores ser compreendida exatamente como um processo que deve continuar após o término do curso da formação inicial. Sem dúvida, proporcionar condições para que os professores possam continuar a estudar e a aprender, enfim, a aperfeiçoar sua prática e a ação educativa que desenvolvem é fundamental. Entretanto, se não ficar evidente nas políticas voltadas para a formação e para a profissionalização docente que a licenciatura é momento crucial, pois pode conduzir à consistência teórica e à apropriação das técnicas e conhecimentos necessários para o exercício qualificado da educação das novas gerações, então, temos uma situação em que a formação continuada também perde seu potencial, uma vez que passa a ser concebida unicamente como momento de sanar os problemas que o professor enfrentou e não resolveu no curso de formação inicial.

Valoriza-se aqui esse primeiro momento da formação profissional, que deve ocorrer na universidade ou no ensino superior, porque esta deve estar integrada e articulada com a formação geral e intelectual. A licenciatura pode se constituir em ocasião para que o futuro professor consiga romper com as relações sociais que o produziram até então: "o indivíduo só se emancipa quando se liberta do imediatismo de relações que de maneira alguma são naturais [...]"; e a formação profissional é a oportunidade de os licenciandos “[...] tomarem consciência das dificuldades, da ruptura entre sua existência e sua profissão - e essa consciência deverá inevitavelmente ocorrer na universidade" (ADORNO, 1995a, 67-68). 
Reconhecendo que as principais dimensões e aspectos são contemplados nas diretrizes para a formação dos professores, com temas sociais e educacionais importantes sendo tratados, como a diversidade cultural, os direitos humanos e o meio ambiente, ainda assim conteúdos e experiências relacionadas à educação política (ADORNO, 1995b) dos futuros professores poderiam ser definidos e explicitados de forma mais precisa e contundente.

Nas diretrizes é proposto e defendido que os projetos das licenciaturas devam contemplar a articulação entre teoria e prática, a indissociabilidade ensino, pesquisa e extensão, o que proporcionaria uma "sólida base teoria e interdisciplinar", tornando seus egressos "agentes formativos da cultura" (BRASIL, 2015, p. 23). Se considerarmos que tudo isso é alcançado por meio de uma matriz curricular na qual estão incluídos conteúdos, os mais diversificados, ainda que todos de fato digam respeito à educação, pode-se concluir que são os próprios estudantes os responsáveis por articular sua experiência no ensino superior. Destaque-se o seguinte excerto das diretrizes:

Os cursos de formação deverão garantir nos currículos conteúdos específicos da respectiva área de conhecimento ou interdisciplinares, seus fundamentos e metodologias, bem como conteúdos relacionados aos fundamentos da educação, formação na área de políticas públicas e gestão da educação, seus fundamentos e metodologias, direitos humanos, diversidades étnico-racial, de gênero, sexual, religiosa, de faixa geracional, Língua Brasileira de Sinais (Libras), educação especial e direitos educacionais de adolescentes e jovens em cumprimento de medidas socioeducativas. (BRASIL, 2015, p. 51).

Por fim, cabe destacar que as 3.200 horas previstas nas licenciaturas devem ser distribuídas pelos seguintes núcleos (como também ocorre no curso de Pedagogia):

I - núcleo de estudos de formação geral, das áreas específicas e interdisciplinares, e do campo educacional, seus fundamentos e metodologias, e das diversas realidades educacionais [...];

II - núcleo de aprofundamento e diversificação de estudos das áreas de atuação profissional, incluindo os conteúdos específicos e pedagógicos e a pesquisa priorizada pelo projeto pedagógico das instituições;

III - núcleo de estudos integradores para enriquecimento curricular (BRASIL, 2015, p. 29). 
Com toda essa organização complexa recomendada, nada é afirmado sobre como será efetivada a tão almejada integração e articulação de conhecimentos práticos e teóricos. Em outras palavras, salvo a menção ao caráter interdisciplinar a reger o funcionamento das atividades dos cursos, a tarefa de atribuir significado - político, social e educacional - para o aprendizado é menos dos professores formadores e mais do aluno. Imagina-se que todo o conteúdo indicado somente poderá compor a matriz curricular se a ele for dedicado apenas o tempo mínimo necessário, o que dificultará o aprofundamento dos estudos e a consolidação dos conhecimentos adquiridos. Não se trata de se posicionar contrário à incorporação, pelos cursos de formação de professores, de temas fundamentais, sobre os quais incidem a prática pedagógica; mas de chamar a atenção para o fato de que a reflexão sobre as condições objetivas existentes nas universidades e em outras instituições de ensino superior dificultariam (ou facilitariam) a realização dessas diretrizes, isso não é proposto e nem considerado. De certo modo, esse modelo de formação de professores está relacionado com a concepção expressa tanto nas diretrizes do curso de Pedagogia como nas das licenciaturas:

Compreende-se a docência como ação educativa e como processo pedagógico intencional e metódico, envolvendo conhecimentos específicos, interdisciplinares e pedagógicos, conceitos, princípios e objetivos da formação que se desenvolvem na construção e apropriação dos valores éticos, linguísticos, estéticos e políticos do conhecimento inerentes à sólida formação científica e cultural do ensinar/aprender, à socialização e construção de conhecimentos e sua inovação, em diálogo constante entre diferentes visões de mundo (BRASIL, 2015, p. 42).

Compreende-se a docência como ação educativa e processo pedagógico metódico e intencional, construído em relações sociais, étnico-raciais e produtivas, as quais influenciam conceitos, princípios e objetivos da Pedagogia, desenvolvendo-se na articulação entre conhecimentos científicos e culturais, valores éticos e estéticos inerentes a processos de aprendizagem, de socialização e de construção do conhecimento, no âmbito do diálogo entre diferentes visões de mundo (BRASIL, 2006, p. 1).

Percebe-se poucas diferenças entre os dois trechos redigidos com um intervalo de onze anos entre eles. Mas esse não é o aspecto principal que se quer evidenciar. A compreensão sobre o que é o magistério e sobre como deve ser a formação docente aponta para a ampliação das tarefas e obrigações que recaem 
sobre os professores. Mais do que transmitir determinados conhecimentos e valores é necessário abarcar todo um conjunto de situações, que assimiladas por seus alunos, possibilitariam a eles a inserção exitosa na vida social, o que inclui aspectos ligados ao exercício da cidadania, ao mundo do trabalho e às constantes inovações proporcionadas pelo avanço das forças produtivas expressas no desenvolvimento das tecnologias da informação e da comunicação.

Por isso os documentos que estabelecem as diretrizes para a formação de professores precisam ser amplos, justamente para dar conta de todos os aspectos relacionados com a educação das novas gerações. Mas, ao serem assim, por ampliarem as atribuições do professor da educação básica, acentuam os impasses e as indefinições que têm cercado o debate sobre formação inicial e continuada de professores. De fato, tais diretrizes parecem abarcar o que é importante, mas, por isso mesmo, estimulam que tudo seja tratado de forma superficial. Em estudo realizado sobre os projetos pedagógicos de cursos de licenciaturas de universidades federais brasileiras, com foco no modo como serão introduzidos os conteúdos concernentes à educação das pessoas com deficiência, Simões (2016) assinala que os futuros professores não são preparados para lidar com os alunos e suas singularidades, evidenciando uma tendência que leva ao abreviamento dos estudos propostos e ao esvaziamento dos significados de conceitos e termos que expressariam as contradições e toda a complexidade da vida social e da educação escolar.

Ainda sobre a ampla gama de atividades envolvidas na docência, as funções designadas às escolas e à educação em geral tornam a prática dos professores muito fluida, com sua energia sendo diluída em várias frentes de trabalho. Insiste-se, não se defende que os professores devam "virar as costas" para a realidade social que afeta decisivamente a vida de seus alunos, mas parece essencial desenvolver um debate que tenha como meta demarcar claramente o que diz respeito à educação escolar. A esse propósito, recorre-se às formulações de Adorno:

Una escuela abierta por completo hacia fuera, sin trabas ni inhibiciones, perdería posiblemente también lo que en ella hay de acogedor y formativo. [...] Dado, por otra parte, que quienes se mueven en el ámbito escolar no admiten la menor intromisión en su territorio, está claro que la tendencia de éstes a cerrarse en sí mismo tiende a acentuarse, al menos frente a la crítica. [...] Habría que hacer comprender que la escuela no es un fin en sí misma, que su carácter cerrado es una necesidad, no la virtude [...]. (ADORNO, 1998, p. 77). 
Considera-se que a já referida ampliação das tarefas do professor leva a uma abertura ao exterior que coloca em xeque a especificidade de sua atividade profissional. Assim tem-se a impressão de que o ensino propriamente dito é cada vez mais desprestigiado na prática pedagógica. ${ }^{2}$ A diversificação do espectro de atuação, em atendimento às demandas sociais externamente estabelecidas, enseja a definição do magistério nos seguintes termos, entre tantas possibilidades: "aplicação ao campo da educação de contribuições e conhecimentos, como o pedagógico, o filosófico, o histórico, o antropológico, o ambiental-ecológico, o psicológico, o linguístico, o sociológico, o político, o econômico, o cultural" (BRASIL, 2015, p. 50). Ainda que necessária, a ampliação verificada é de tal magnitude que a prática docente perde sua singularidade e a referência historicamente constituída que confere identidade à profissão do magistério. Mais uma vez, essa situação parece agravar os impasses e as ambiguidades presentes nas políticas e propostas de formação do professor.

De certo modo, as diretrizes para os cursos de licenciatura (incluindo a Pedagogia) são determinadas pelas incertezas e imprecisões que perpassam a docência na atualidade. O professor precisa ter conhecimentos e possuir destrezas que o habilite a ensinar seus alunos, precisa ser um gestor educacional, precisa ser um especialista nas ciências da educação, precisa também agir sobre os aspectos socioculturais que estão presentes na realidade da escola e que interferem em seu trabalho. E ele só pode dar conta de tudo isso se abrir mão da formação profissional propriamente dita e colocar em prática os parcos conhecimentos adquiridos em cada âmbito, atuando muito mais de modo técnico do que pedagógico e político. Talvez cursos mais bem dimensionados garantissem a especificidade e uma formação que subordinasse a técnica (compreendida como meio) às finalidades sociais e democráticas da educação.

Tendo como referência os conceitos de pseudoformação de Adorno (1966) e de racionalidade tecnológica de Marcuse (1969; 1999), analisou-se as tendências presentes nas diretrizes para a formação de professores da educação básica em cursos de nível superior. Entende-se que o ensino superior no Brasil está envolto no que Adorno (1966) denomina de ideologia da pseudodemocracia, pois a maneira como os bens culturais chegam àqueles que antes não tinham acesso à cultura é determinada pelo desenvolvimento econômico e tecnológi-

2 Em estudo no qual é analisado um conjunto de livros didáticos para o $5^{\circ}$ ano do ensino fundamental, Galuch e Crochík (2016, p. 247) afirmam: "no lugar do ensino pelo professor, institui-se a organização de situações em que o aluno, por si, se torna o seu próprio guia [...]". Assim, verifica-se uma tendência geral presente em todos os lugares, incluindo as diretrizes e as políticas educacionais, a partir do que as reformas curriculares se constituem em propostas que "diluem a autoridade do professor e a obrigatoriedade da transmissão do conhecimento". (GALUCH; CROCHÍK, 2016, p. 234). 
co - orientado, é claro, pela lógica do capital e da mercadoria. O fato de que cada vez mais pessoas possam ter acesso aos bancos das instituições de ensino superior não significa a vitória da formação cultural. Muito pelo contrário: a elevação do nível da técnica, que permite maior eficiência, e do padrão de vida, que de fato proporciona melhora nas condições de existência das classes menos abastadas, militam a favor da pseudocultura. Tal conceito foi cunhado por Adorno (1966) para designar o modo como a cultura está configurada sob o capitalismo monopolista - que se desenvolveu de forma vertiginosa no século XX e, especialmente, depois da II Guerra Mundial.

De um lado, temos a persistência da noção de que a cultura é algo "sacrossanto", com sua elevação a um plano que a coloca acima e além da existência material, o que produz sua negação à maioria da população; de outro, foi convertida em meio para a conformação à vida, com a valorização das manifestações que produzem o conformismo e a adaptação à ordem estabelecida e ao status quo (ADORNO, 1966). A sua consideração como algo vivo e dinâmico, o que proporcionaria aos indivíduos seu próprio refinamento, a relação que produziria certa tensão entre seus limites e possibilidades e apontaria para sua necessária renovação, parece ser cada vez mais impedida de se realizar. É dessa perspectiva que se assevera que a pseudoformação se afigura como a tendência prevalecente nos cursos de formação de professores. A utilização do prefixo pseudo indica o conteúdo de falsidade presente nos processos de formação dos indivíduos, seja na escola, na família ou em outros espaços nos quais acontece a interação social. Assim a pseudoformação pode ser definida como modelo de socialização que promove predominantemente a adesão acrítica à ordem social, já que a formação cultural propriamente dita, ou seja, a apropriação subjetiva da cultura (ADORNO, 1966), que forneceria mínimas condições para a promoção da autonomia, é impedida de acontecer.

É Marcuse (1999) quem esclarece o modo como esse processo acontece. A racionalidade tecnológica impõe desempenhos padronizados, sendo em função disso que as distinções individuais são produzidas. E o mais importante: ocorre a submissão racional aos fatos:

Os fatos que dirigem o pensamento e a ação do homem não são os da natureza, que devem ser aceitos para que possam ser controlados, ou aqueles da sociedade, que devem ser modificados porque já não correspondem às necessidades e potencialidades humanas. São antes os fatos do processo da máquina, que por si só aparecem com a personificação da racionalidade e da eficiência (MARCUSE, 1999, p. 79). 
Destaque-se que os cursos de formação de professores, ainda que expressem as contradições e ambiguidades presentes na sociedade administrada, enquadram-se nesse modelo que prima pelos desempenhos especializados, de um lado, e que promovem a aceitação dos valores da economia política e a padronização do comportamento, de outro. É dessa maneira que se concebe aqui o nexo entre pseudoformação e racionalidade tecnológica. A esse propósito, Marcuse (1969, p. 154) acentua o fato de a tecnologia se estabelecer como forma de controle e dominação social. A razão, transfigurada em racionalidade tecnológica, sucumbe à "sociedade racionalmente totalitária".

Portanto, enfatiza-se que o aparato tecnológico está a serviço do poder. Insiste-se que, embora as licenciaturas contenham elementos que podem promover a autorreflexão, a pseudoformação, como consequência da submissão à racionalidade tecnológica, parece ser o resultado mais tangível quando se analisa os documentos em tela.

Parece prevalecer a noção de que o professor, se bem capacitado e compromissado com a causa dos alunos, pode sozinho fazer a diferença. Esse posicionamento reforça o que Marcuse (1972) identificou no desenvolvimento da filosofia burguesa: ante a sensação de impossibilidade de transformar a ordem social injusta, que produz a desigualdade entre os homens, resta a cada um solitariamente lutar para que seus interesses e sua autonomia se realizem. Assim a liberdade é algo que se conquista individualmente ou que se constitui em um dado a priori. E só pode ser alcançada no plano da interioridade, inocentando a sociedade e as condições objetivas de vida da responsabilidade por impor as determinações sociais que limitam e reduzem à experiência dos indivíduos.

Verifica-se a intenção de que sejam produzidas condições subjetivas para a adaptação à sociedade. Assim a educação é concebida como prática que deve promover situações que levem a tais mudanças. Esse entendimento não é algo novo e um autor interessando nos vínculos entre educação e sociedade, nas décadas de 1940 e 1950, já apontava nessa direção. Dessa perspectiva, a educação deveria ser planejada "[...] de modo que se integre [cada indivíduo] nos padrões vigentes de interação e organização social” (MANNHEIM, 1987, p. 325). Infelizmente, nos cursos de formação inicial de professores, parece prevalecer a tendência que os transforma em instrumento para a adaptação das novas gerações aos padrões sociais marcadamente vinculados à lógica da dominação. Torna-se oportuno relembrar autores da sociologia funcionalista, como Karl Mannheim, porque apesar das várias críticas formuladas a essa posição teórica, verifica-se que propostas feitas a mais de 60 anos - e já superadas - continuam presentes no pensamento educacional. A premissa básica que aparentemente orienta os cursos de formação é a seguinte: "[...] as pessoas têm de ser condicionadas e educadas para se integrarem nos padrões vigentes de vida social” (MANNHEIM, 1987, 
p. 325). Sabemos o que isso significa: mais importante que a formação para a autonomia é a adaptação à sociedade burguesa e à divisão social do trabalho ensejada por ela.

Então, verifica-se toda a ambiguidade nas diretrizes: ainda que sejam percebidos os limites da educação, que sejam conhecidos os problemas que impedem o florescimento de práticas educativas alternativas e inovadoras, ainda assim defende-se o engajamento de todos à causa da educação (professores formadores e futuros ingressantes na carreira do magistério). Mas para fazer isso são obrigados a abrir mão da crítica, neutralizando o potencial de formação que uma perspectiva política assumida a partir do contato com os temas da educação poderia ter. É exatamente esse o conteúdo da formação cultural, tal como Adorno (1966) a define. Para esta ocorrer seria necessária a apropriação subjetiva da cultura por parte dos indivíduos, como já salientado, o que significa ter as condições e a possibilidade de transcender a mera adaptação e de resistir àquilo que impede a transcendência. Portanto, a formação não é outra coisa senão, a partir da capacidade de fazer experiências - inclusive as intelectuais de modo livre e espontâneo, desenvolver a consciência acerca de si mesmo e do outro, utilizando para isso todas as potencialidades adquiridas e desenvolvidas (ADORNO, 1995). No entanto, quando se vive em uma sociedade que impõe limites desde muito cedo, resta-nos somente a pseudoformação.

$\mathrm{O}$ exame das diretrizes para a formação de professores permite concluir que a atuação na área da educação deve estar revestida de um caráter político, mas sem que isso signifique o próprio questionamento das políticas educacionais e da ordem social. De qualquer modo, verifica-se o reconhecimento dos problemas enfrentados pela escola, o que não é pouco. Os futuros professores são instados e arrastados a empreender um esforço quase sobre-humano para direcionar seus interesses para as questões técnicas da prática pedagógica, pois se valoriza muito mais a intervenção imediata, deixando em segundo plano a reflexão e a autorreflexão. Outra conclusão é a de que prevalece a crença de que a atuação competente e qualificada, independentemente das condições objetivas, pode fazer a diferença. Portanto, ainda que sejam politizadas as práticas dos professores, pois visam o enfrentamento dos problemas sociais e educacionais, são valorizadas as iniciativas isoladas e individuais. Por fim, a formação do professor, expressando a situação geral da pseudoformação socializada (ADORNO, 1966), que produz uma espécie de alienação consciente, está envolta nas contradições presentes na sociedade burguesa e capitalista dos tempos atuais. Exprime, igualmente, o modo como a racionalidade tecnológica se afirma como modelo de competência, valorizando e elevando à condição de mito o desempenho eficiente, mesmo quando esse é impossível, como parece ser o caso da educação escolar. É impraticável imaginar, nessa sociedade, uma 
escola que não reproduza a desigualdade, que não produza indivíduos envoltos na pseudoformação e deformados, enfim, que não reproduza o próprio fracasso da escola. O que é o oposto da eficiência, uma vez que parece estar em curso uma tendência que fará com que um número elevado de alunos saia dela sem as condições mínimas para sequer se adaptar e se integrar na sociedade. Se os cursos de formação de professores produzirem a consciência desse fato já estarão oferecendo uma fundamental contribuição, pois ficarão evidenciadas a necessidade da transformação social e os nexos intrínsecos entre a escola pública (seus limites e possibilidades) e as contradições sociais, incluindo as de ordem política e econômica.

\section{REFERÊNCIAS}

ADORNO, T. W. Teoría de la seudocultura. In: HORKHEIMER, M.; ADORNO, T. W. Sociologica. Madrid: Taurus Ediciones, 1966, p. 175-199.

ADORNO, T. W. Educação - para quê? In: ADORNO, T. W. Educação e emancipação. São Paulo: Paz e Terra, 1995, p. 155-168.

ADORNO, T. W. A Filosofia e os professores. In: ADORNO, T. W. Educação e emancipação. São Paulo: Paz e Terra, 1995a, p. 51-74.

ADORNO, T. W. Educação após Auschwitz. In: ADORNO, T. W. Educação e emancipação. São Paulo: Paz e Terra, 1995b, p. 119-138.

ADORNO, T. W. Tabúes sobre la profesión de enseñar. In: ADORNO, T. W. Educación para la emancipación. Madrid: Ediciones Morata, 1998, p. 65-78.

BRASIL. Ministério da Educação. Resolução CNE/CP Nº 1/2006, de 15 de maio de 2006. Institui Diretrizes Curriculares Nacionais para o Curso de Graduação em Pedagogia, licenciatura Conselho Nacional de Educação - Conselho Pleno, Brasília, 2006.

BRASIL. Ministério da Educação. Parecer CNE/CP No 2/2015, de 9 de junho de 2015. Diretrizes Curriculares Nacionais para a Formação Inicial e Continuada dos Profissionais do Magistério da Educação Básica Conselho Nacional de Educação - Conselho Pleno, Brasília, 2015.

GALUCH, M. T. B.; CROCHÍK, J. L. Propostas pedagógicas em livros didáticos: reflexões sobre a pseudoformação. Cadernos de Pesquisa. São Paulo, v. 46, n. 159, p. 234-258, jan./mar. 2016.

MANNHEIM, K. A crise da sociedade contemporânea. In: PEREIRA, L.; FORACCHI, M. M. Educação e sociedade. 13 ed. São Paulo: Editora Nacional, 1987, p. 321-342. 
MARCUSE, H. Algumas implicações sociais da tecnologia moderna. In: MARCUSE, H. Tecnologia, guerra e fascismo. São Paulo: Editora UNESP, 1999, p.71-104.

MARCUSE, H. Ideologia da sociedade industrial. Rio de Janeiro: Zahar Editores, 1969.

MARCUSE, H. Estudo sobre a autoridade e a família. In: MARCUSE, H. Ideias para uma teoria crítica da sociedade. Rio de Janeiro: Zahar Editores, 1972, p. 56-159.

SIMÕES, M. C. D. Formação do indivíduo, formação docente e educação especial: o lugar do sujeito e o compromisso com a adaptação. 2016. 165 f. Tese (Doutorado em Educação) - Pontifícia Universidade Católica de São Paulo (PUCSP), São Paulo, 2016.

Texto recebido em 03 de novembro de 2016.

Texto aprovado em 13 de abril de 2017. 